International Journal of Language Education

Volume 5, Number 4, 2021, pp. 271-284

ISSN: $2548-8457$ (Print) 2548-8465 (Online)

Doi: https://doi.org/10.26858/ijole.v5i4.19320

\title{
Reducing the Impact of Pandemic on Chinese Language Education in the Philippines through the Localization of Chinese Teachers
}

\author{
Cavin F Pamintuan \\ Angeles University Foundation, Philipines \\ Email:pamintuan.cavin@gmail.com
}

Received: 17 February 2021

Reviewed: 1 August 2021-30 October 2021

Accepted: 1 December 2021

\begin{abstract}
This descriptive research focused on the localization of Chinese teachers in the Philippines and how it became instrumental in reducing the impact of COVID-19 pandemic on Chinese language education. Through the review of existing studies and pertinent documents such as memorandum orders, agreements and training plans, this paper provided an in-depth analysis of the current situation of localization of Chinese teachers. Currently, there were three (3) modes of cultivating local teachers for Chinese language teaching, namely in-service teachers' training, undergraduate degree program and master's degree program. The mentioned programs have been successful in producing local teachers who are capable of teaching Chinese as a foreign language. Furthermore, it is through the local teachers that the impacts of the pandemic on Chinese language education in the Philippines have been reduced. The localization of Chinese teachers has been of great help in addressing the challenge of not having volunteer Chinese teachers and uniformed instructional materials in the midst of pandemic. Moreover, opportunities for the localization of Chinese teachers were also discussed. Lastly, guided with the findings and conclusions, the paper provided recommendations for further development of Chinese language education in times of pandemic or other natural calamities which may disrupt the face-to-face classes.
\end{abstract}

Keywords: Chinese as a Foreign Language (CFL); Localization of Chinese Teachers; Local Chinese Mandarin Teachers

\section{Introduction}

The COVID-19, which was categorized as pandemic on March 11, 2020 by the World Health Organization, has caused the widest disruption in education systems in history (WHO, 2020). More than a billion students across all countries in all continents have been affected by the pandemic. The most severely affected country was the Philippines. In order to slow down the 
spread of the disease, the government mandates the temporary closure of establishments, including schools. The disruption of classes caused by school closures has forced the shifting of the mode of instruction delivery from face-to-face to online, and this was the last option of schools in order for them to continuously deliver their commitments to students amidst the pandemic and to completely end the academic year. Face-to-face classes were suspended indefinitely and the only way to continue learning is through online platforms or virtual classrooms. Since physical classes were suspended indefinitely, Chinese Volunteer Teachers (CVT) were advised to go back to China. Moreover, the existing travel ban may prevent the CVT from coming back to the Philippines or any other countries to teach the language. Similar in any other countries, absence of CVT may hinder the continuous implementation of Chinese classes. The lack of teachers was also the same dilemma during the pioneer years of the inclusion of Chinese Mandarin in the Special Program in Foreign Language of then newly reformed national education system of the Philippines (see, 2012). The same problem is also existing among Chinese schools in the Philippines. In addition to that, the quality and professional degree of Chinese teaching staff remained low (Yang, 2014). It is because an education degree is not a requirement to teach Chinese in the Chinese schools of the Philippines, hence, teachers teaching Chinese language don't have the pedagogical skills to properly teach Chinese and motivate students to learn the language (Palanca, 2002). Thus, Chinese schools opted to adopt a short-term solution called "transfusion method," which is to import native Chinese Teachers. The said method is effective in alleviating the urgent needs for Chinese Mandarin teachers (Bee, 2012; Zhang, 2012). The said method is the principle behind the Chinese Volunteer Teacher Program of the Confucius Institute Headquarters, which aim to provide volunteer teachers to address the shortage of Chinese teachers in other countries (Hanban, 2020). The Chinese Volunteer Program or the deployment of Chinese volunteer teachers in a foreign country is a band-aid solution that would solve the problem of not having enough local teachers who will teach Chinese language (Starr, 2009).

The first batch of Chinese volunteer teachers in the Philippines, consisting of 19 teachers, was deployed by the Confucius Institute Headquarters in 2013 (Fan, 2015). However, importing Chinese volunteer teachers may only be applicable to Chinese and private schools in the Philippines. This is not applicable in the Philippine public-school system because of existing policies which prohibit any foreigner to teach in the public school. In addition, CVTs are only allowed to stay in a foreign country for one to two years. Therefore, to ensure the sustainable development of the Chinese language education in the Philippines, the Confucius Institute at Angeles University Foundation (CI-AUF) and the Philippine Department of Education explored the long-term solution, which is the localization of Chinese teachers in the Philippines. Localization refers to the process of making a particular service or product more appropriate or suitable to the targeted audience in a particular country (Cambridge, 2020). Therefore, localization of Chinese teachers means cultivating local teachers for Chinese language education. According to Yang (2014), the shortage of Chinese teachers can only be solved through the cultivation of local teachers to teach Chinese, it will not only result to an effective Chinese language teaching, it will also provide stable Chinese faculty. According to Zhang (2010), the best Chinese teacher is someone who is proficient in both Chinese Mandarin and local language, and share the same cultural and linguistic backgrounds with the learners. The difficulties of Chinese volunteer teachers to use English in expressing some language concepts may hinder the students to better understand Chinese Mandarin, however, the local teacher can use local language or dialect to let the students learn the concept easily. In addition, some teachers who don't have sufficient teaching experience and professional training in language pedagogy, used traditional teaching methodology of 
Mainland China and consider foreign students studying Chinese language in the Philippines as Chinese mother-tongue students (Adil et al., 2020).

The localization of Chinese teachers will not only contribute in a more contextualized Chinese language teaching, it will also ensure the sustainable development of the Chinese language program in the Philippines even during natural calamities such as pandemic when CVTs are not available. In order to realize the vision of the Philippine Department of Education, which is to cultivate local teachers for Chinese language education for its Special Program in Foreign Language (SPFL-Chinese Mandarin), it gave the CI-AUF the authority to be the Training Center for the Chinese Teachers in the Philippines in 2013. The CI-AUF designed three training programs to train local Chinese teachers, namely In-Service Teacher's Training, Bachelor Degree for Chinese Language Teaching and Master Degree for Chinese Language Teaching. These training programs have varied targeted trainees; however, they were interrelated and aim to achieve one common goal, and that is to produce qualified local Chinese teachers.

The inclusion of foreign languages in the national curriculum of the Philippines has already been ten (10) year, but not much scientific work has been done to provide an in-depth analysis of its implementation. Therefore, to contribute in this field of knowledge and fill in the gap, this study explored the localization of Chinese teachers in the Philippines and how this can reduce the impact of the pandemic. Specifically, the study pursued to answer the following questions:

1. What is the current state of Localization of Chinese Teachers in the Philippines?

2. What are the opportunities and challenges in the Localization of Chinese teachers in the Philippines during the pandemic?

3. What are the implications of this study to the Chinese language teaching in the Philippine public high schools?

This study can serve as a reference material for the future developments of Chinese language teaching under the Special Program in Foreign Language of the Department of Education. Since the geographical location of the Philippines is prone to natural calamities such as typhoon and earthquake, which would definitely hinder the deployment of Chinese volunteer teachers, stakeholders shall craft the developmental plan for the continuous localization of Chinese teachers to ensure the continuity of Chinese language teaching, even without the physical presence of Chinese volunteer teachers or trainers. The study has a great significance to the researchers exploring the localization of foreign language teaching in the Philippine basic education system. Moreover, this study can provide valuable inputs to both teachers and school heads on how they can further enhance the implementation of SPFL-Chinese Mandarin, even during this pandemic.

\section{Materials and methods}

Research design

This study utilized qualitative research design. According to Aspers \& Corte (2019), qualitative research refers to the process of analyzing empirical data iteratively in order to make distinctions and to provide the scholarly community an improved understanding of a particular phenomenon. Corbin and Strauss (2015) defined qualitative research as a research approach which is independent to quantitative data or any statistical treatment. In order to determine the current situation of the localization of Chinese teachers in the Philippines, this study reviewed pertinent documents retrieved from official webpages of the Philippine Department of Education, China's Center for Language Education and Cooperation, and Confucius Institute Headquarters. Moreover, existing studies on Chinese language education in the Philippines were also revisited to provide an in-depth analysis. 
Materials

This study accessed the official webpages of the Confucius Institute Headquarters, Center for Language Education and Cooperation and Philippine Department of Education to gather empirical data that would describe the localization of Chinese teachers in the country. Documents that were accessed include news articles, department memorandum orders, agreements, conference proceedings and pertinent presentations. Moreover, related studies were also revisited to provide a holistic overview of the situation of Chinese language education in the Philippines.

\section{Result and discussion}

Teachers' training program for Chinese language education in the Philippines

The Philippine Department of Education launched its Special Program in Foreign Language in the selected public high schools in 2009 and offered Spanish, Japanese and French. German was added among the foreign languages in 2010, while Chinese Mandarin was included in 2011 (DepEd, 2012). The latest language to be included in the SPFL is the Korean language, which was added in 2017. The main goal of the SPFL is to produce multilingual Filipino learners who are globally competitive. The table 1 below shows the data of SPFL as of July 2019, a decade after its initial implementation (Gusano, 2019).

To address the urgent needs of the SPFL for qualified foreign language teachers, the DepEd establishes a training session for in-service language teachers. With this scheme, the imported foreign language teachers will serve as trainers of the teachers. Among all the languages included in SPFL, the Chinese Mandarin has the highest school to teacher's ratio (1:3), having at least three trained local teachers in every school. The high ratio was a product of a systematic training program for the localization of teachers for Chinese language education in the Philippines

Table 1. Special Program in Foreign Language 2019 Data

\begin{tabular}{cccccc}
\hline Language & Schools & Teachers & Students & Year Started & Partner Institution \\
\hline Spanish & 83 & 190 & 3531 & 2009 & Instituto Cervantes \\
Japanese & 38 & 92 & 5020 & 2009 & Japan Foundation \\
French & 12 & 23 & 1112 & 2009 & Alliance Francaise \\
German & 9 & 20 & 983 & 2010 & Goethe Institut \\
Chinese & 93 & 310 & 11000 & 2011 & Confucius Institute \\
Korean & 18 & 36 & 800 & 2016 & Korean Cultural Center \\
Total & 253 & 661 & 22446 & & \\
\hline
\end{tabular}
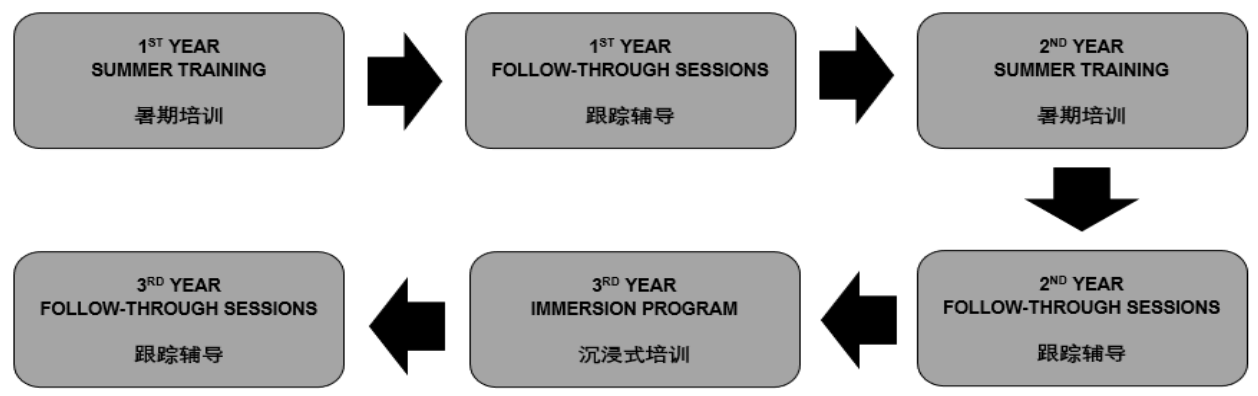

Figure 1. Training Plan for In-Service Teachers

In-service teacher's training 
The in-service teacher's training program is a 3-year program intended for teachers of the public-school system who are currently teaching language (English or Filipino). The Chinese Volunteer Teachers served as trainers of the prospective teachers of Chinese Mandarin. The training is a combination of on-campus, in-house and overseas training. It is composed of three major parts, namely summer training, follow-through sessions and immersion program. In able for a prospective teacher to teach Chinese Mandarin in his school, his level of proficiency should be at least one (1) level higher to the class he is handling. The teacher with HSK Level 2 proficiency can handle a class which target proficiency is Level 1. The figure 1 shows the training plan for inservice teachers.

The prospective teachers will have their summer training and follow-through sessions in the first year of the training. During the first summer training, prospective teachers will have an on-campus intensive training at the Confucius Institute at Angeles University Foundation. Their month-long training with total of 160 hours aims to provide the fundamentals of the Chinese language and culture. At the end of the first summer training, the prospective teachers are expected to pass the HSK 1 (CEFR A1). Their training will be continued in their respective schools by assigning Chinese Volunteer Teacher in each school. The follow-through training is the supervision of instruction of local Chinese teachers and further enhancement of their foreign language proficiency. The duration of the follow-through session is thirty-two (32) Saturdays and covers atleast 100 hours. The role of the CVT is to observe Chinese classes of those teachers who are already qualified to teach Chinese Mandarin and to provide feedback. Furthermore, they will provide weekend Chinese language classes to enhance the proficiency of the local teachers. This strategy aims to sustain the proficiency of the teachers and to prepare them for the second summer training in the following year.

The second year of the training includes another 160-hour on-campus training and atleast 100-hour in-house training. The targeted level of competency after the second summer training is HSK 2 (CEFR A2), although its coverage already covers some parts of the HSK 3 (CEFR B1). On the other hand, the second year of follow-through sessions will prepare the prospective teachers to pass HSK 3 (CEFR B1) prior to the immersion program in the following year.

The third year of the training will be an overseas training, prospective teachers will be sent to China for one-month training program. The Local Chinese Language Teachers' Training Program aims to provide the local teachers of Chinese language in a foreign country the support for their professional development through a short-term professional training in China (CLEC, 2020). This will serve as an opportunity for them to fully practice their Chinese language in a realworld setting. The language environment will further enhance their fluency in Chinese Mandarin. The coverage of this training ranges from HSK 3 (CEFR B1) to HSK 4 (CEFR B2).

For the past ten years, the AUF-CI has trained a total of nine (9) batches of local teachers with a total of three hundred twenty-one (321) in-service teachers from ninety-three (93) public high schools. The figure 2 below show the number of trained teachers in every year. 


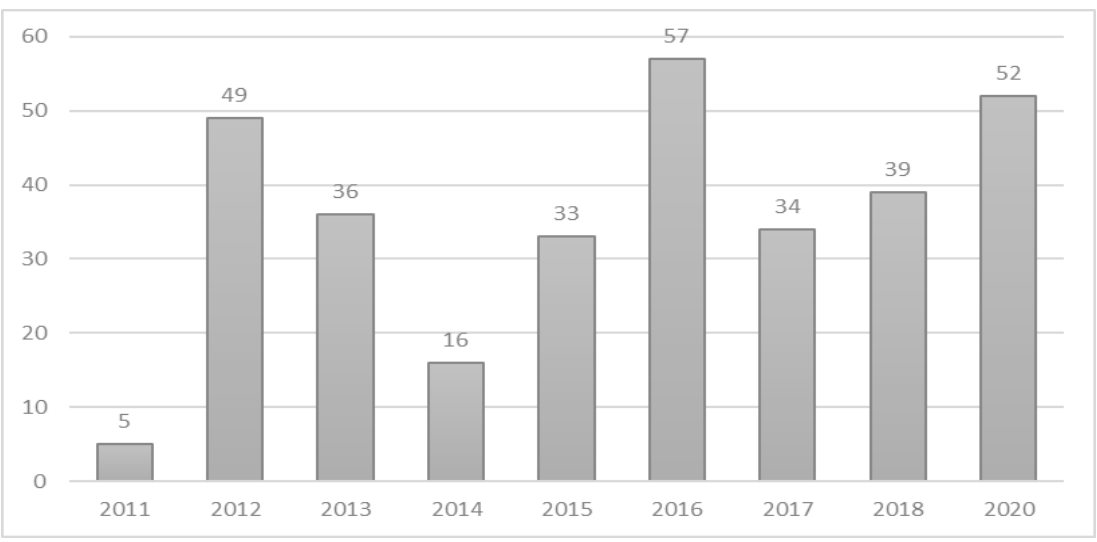

*There was no training in 2019 due to the earthquake that happened in Pampanga, Philippines

Figure 2. Number of Trained Local Teachers for Chinese in the Philippines

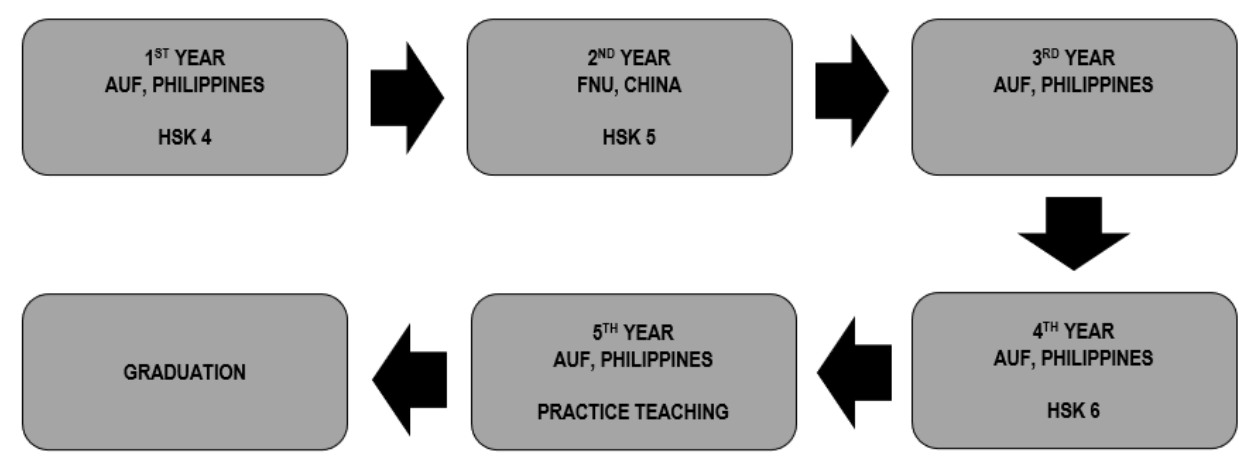

Figure 3. Training Plan for BSEd CLT Program

\section{Bachelor of secondary education major in Chinese language teaching}

In order to support the development of Chinese language teaching of foreign countries, the Confucius Institute Headquarters establish partnership with foreign universities to develop a Chinese language teacher program (Hanban, 2020). As a result of this project, the Confucius Institute Headquarters and AUF-CI jointly establish the Bachelor of Secondary Education major in Chinese Language Teaching (BSEd CLT). The said program aims to further address the scarcity of qualified teachers for Chinese language education in the Philippines. It is a five-year undergraduate course which aims to produce professional Filipino teachers that would teach Chinese language. The BSEd CLT program paves the way of the professionalization of local teachers for Chinese language education. Aside from Chinese, students in this program will also major English, which will make them qualified to take the Licensure Examination for Teachers of the Philippines. Students under this program are the most outstanding graduates of the Special Program in Foreign Language of the Department of Education and were recommended by their school heads. The students have an agreement with DepEd and AUF-CI, wherein they will render five years of return service in the public high school where they graduated after completing the BSEd CLT program. The figure 3 below shows the training plan for the BSEd CLT program.

The curriculum of the BSEd CLT program approved by the Philippine Commission on Higher Education has a total number of two hundred thirty (230) units or equivalent to twelve thousand four hundred twenty $(12,420)$ hours of instruction. It is composed of sixty-six (66) units of Chinese courses, sixty-three (63) units of English courses, and one hundred one (101) units of 
professional and general education courses. From 2014 to 2019, there were seventy-eight (78) students who were enrolled in this program. To ensure that the students will have enough exposure to the foreign language, non-credit courses were also organized to provide them the opportunity to continue learning even after class hours.

\section{Master of Arts in education major in Chinese language teaching}

The Master of Arts in Education major in Chinese Language Teaching (MAEd CLT) is a joint program of the Philippine Department of Education and China's Confucius Institute Headquarters which aims to provide further support to the sustainable development of the Special Program in Foreign Language-Chinese Mandarin (DepEd, 2019). Both in-service teachers and BSEd CLT graduates are qualified to this program. This is to provide opportunity for the SPFLChinese Mandarin teachers the opportunity to have continuous professional development. The MAEd CLT is a two-year program covering six (6) semesters, four (4) of which 4 will be taken in the Philippines and two (2) of which will be taken in China. The targeted level of proficiency for the MAEd CLT program is atleast HSK Level 5 (CEFR C1). The success of the said program will lead to the possible opening of Chinese courses in the senior high school level. The lack of local teachers with higher level of Chinese language proficiency hinders the further offering of Chinese courses in the pre-college level of the basic education. The number of units required to complete the said degree is forty-two (42). The figure 4 below shows the training plan for the MAEd CLT program.

The role of localization of Chinese teachers in addressing the challenges and opportunities in Chinese language education of the Philippines during the pandemic

The abrupt disruption of classes, indefinite suspension of face-to-face instruction, and unavailability of Chinese Volunteer Teachers in the Philippines have brought challenges to the implementation of the Special Program in Foreign Language-Chinese Mandarin. However, the pandemic also stimulates innovations not only in language education but across all disciplines

\section{Challenges}

Chinese volunteer teachers

The biggest challenge faced by the Chinese language education in the Philippines and other countries is the absence of Chinese Volunteer Teachers. The Philippine government-imposed travel restrictions prohibit any international flight to fly to the country, including flights coming from China. This hindered the deployment of Chinese Volunteer Teachers in the Philippines. However, the absence of Chinese Volunteer Teacher did not have a direct impact in the implementation of the Special Program in Foreign Language of the public high schools because of the presence of three hundred twenty (320) trained local teachers. On the other hand, partner private schools implementing Chinese language program were also given the option to hire graduates of BSEd Chinese Language Teaching program, who are also qualified to teach the said foreign language. It is because of the localization of Chinese teachers through in-service teachers' training and BSEd CLT program why the Chinese language education in the mainstream society of the Philippines remained undisrupted even during this pandemic. The vision of the Confucius Institute in the localization of Chinese teachers in the Philippines is to have enough qualified local teachers that will teach Chinese as a foreign language. 


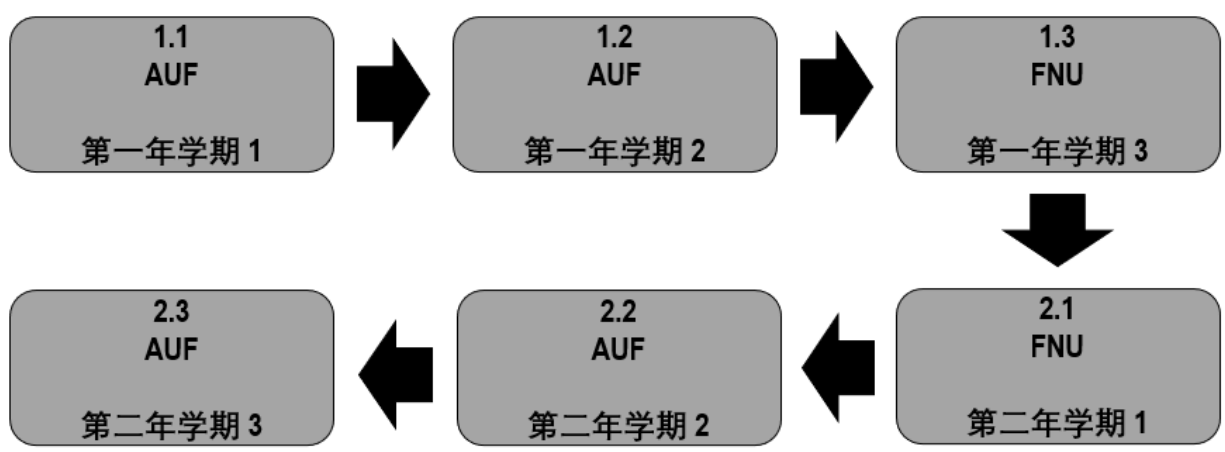

Figure 4. Training Plan for MAEd CLT Program

\section{Instructional materials}

Another challenge arouse due to the pandemic was the unavailability of learning materials. In the traditional classroom, the trained teacher would usually prepare a presentation and learning activity sheets that will be distributed to the students. Since face-to-face instruction was still not allowed, the Philippine Department of Education crafted different learning delivery modalities including distance learning, blended learning and home-schooling. All the mentioned modalities have a common denominator and that is their need of a learning material. However, another feature of the localization of Chinese teachers in the Philippines is the localization of instructional materials. Since Chinese language was not just merely imported in to the education system of the Philippines, it was ensured through localization the alignment between teachers' training, curriculum, targeted competencies of the students, instructional materials, assessment, and evaluation. While the Confucius Institute provided localized instructional materials, which are written in local language, further revisions were made in accordance to the actual local setting, which makes the content of the material closer to the lives of the students. According to Tribus (2017), the diverse cultural background of learners can be used to enrich the materials for the whole class. The revisions in the materials were reflected in the lesson matrices of the teachers. This course of action has been instrumental in solving another problem in the Chinese language education of the Philippines raised by Yang (2014), which is the non-uniformed and diversified teaching materials in Chinese. Therefore, with the uniformed and localized instructional materials and lesson matrices, the shift of learning modality from the traditional setup to distance learning or blended learning was much easier.

\section{Opportunities}

\section{Flexible learning}

In response with the pandemic, the Philippine Department of Education crafted its Learning Continuity Plan which enumerated the different learning delivery modalities that can be implemented among the schools. There are three (3) learning delivery modalities, namely distance learning, blended learning and home-schooling. In the mode of distance learning, students will be given learning modules which can be digitized or printed depending on the student. While in the mode of blended learning, digitized or printed module will be blended with instruction available online, on radio or on television. Lastly, in the mode of home-schooling, a student will have an inhouse class facilitated by a qualified tutor or teacher. These learning deliver modalities were not only applicable during pandemic but also during any other class disruptions caused by natural calamities such as typhoon or earthquake. Therefore, for the future development of the Chinese language education in the Philippines, the stakeholders can come up with a particular program that 
would have flexibility in its delivery. Students who can't come to school will still have the opportunity to learn the language through other modes of learning. This setup will also be applicable to those interested learners who don't have a fixed working schedule. They can access learning materials and learn the language on their most convenient time and venue

\section{Teacher resources}

Countries across the world has been utilizing educational technologies to provide support to remote learning and ensure the continuity of learning in the midst of COVID-19 pandemic (World Bank, 2020). The Philippine Department of Education explored the use of online instruction, radio-based instruction and tv-based instruction to ensure that all students will be given an access to the distance education while schools remain closed. The pandemic, alongside with the advent of the fourth industrial revolution, has opened more opportunities to improve Chinese language education, including the extensive and rich instructional resources in Chinese language teaching.

For the first year in ten years, the training for the prospective Chinese Mandarin as foreign language teachers of the Philippine Department of Education was delivered through an online platform. The monthlong summer training was delivered through a learning management system where the prospective teachers attended both synchronous and asynchronous sessions. Synchronous sessions were allotted for the delivery of instruction by the trainer, while asynchronous sessions were allotted for the accomplishment of activities, discussions, forums, and exercises. Prospective teachers were given the opportunity to complete their learning modules in their most convenient time, making the learning self-directed rather than the traditional teacherdirected learning. The online distance training served as the new approach in the localization of Chinese teachers in the Philippines. The physical presence of the trainer is not necessarily needed, thus, teachers in China can also provide trainings to the prospective teachers, without physically coming to the country. The said mode of training is very applicable during the pandemic when Chinese teachers are not allowed to go to the country because of the existing travel restrictions. Moreover, for an archipelagic country like the Philippines, it is easier to organize a virtual training than inviting all the participants from the different islands to come in a particular place for the training.

The said mode of training is the same to those available Massive Open Online Courses (MOOC) in the internet such of that in Alison and Coursera. The Confucius Institute has its own webpage (https://mooc.chinesecio.com/) for its MOOC. Moreover, the said platform also showcases various collections of instructional and learning materials for Chinese language. Through the said platform, students and teachers across the countries can access resources that would help them enhance their teaching and learning of the Chinese language. As part of the localization of Chinese teachers, the Confucius Institute in each country should consider developing an online platform or learning management system for both teachers and students. The said platform can be written in the local language to attract more learners to learn Chinese Mandarin. Moreover, localized materials, presentations, and lesson plans can be uploaded in order to further enrich the Chinese language teaching in the said country. This platform will be a significant help especially to those who are new in Chinese language teaching. However, not all the students have an access to the internet, according to UNESCO (2020), there were 706 million students who do not have access to the internet and 56 million students living in places where mobile networks are not yet available. The same scenario in some areas in the Philippines where 
students do not have access in the internet or even mobile networks. Thus, another innovation that can be explored is the Radio-Based or TV-Based Instruction.

To ensure that all students in all levels of society will be given the support to continue their learning, the Philippine Department of Education explored the delivery of instruction through Radio and Television. There was a designated radio frequency and tv channel for the remote classes of the students. The content which was delivered through online portals can be broadcasted in both radio and television, provided, a supporting printed material is given to ensure that the students will engage themselves in learning by accomplishing exercises or activities during and after the class.

In case of far-flung villages where radio frequencies were not strong, the last option that can be explored is the use of learning modules. Learning modules are self-directed learning materials which are distributed to the students weekly. Every after week, the teacher will retrieve the learning modules to check the accomplished work of the students. The availability of localized instructional materials has been instrumental in crafting learning modules for the students.

Implications of This Study to the Chinese Language Teaching in the Philippine Public High Schools

The K-12 law of the Philippines mandates the use of local contexts and scenarios in language teaching in order to simulate the use of the target language in the real-life setting (Labiste $\mathrm{Jr}$, 2019). Teaching of the mother tongue, Filipino and English language can be easily contextualized because of the presence of a linguistic environment where students can use the language even after their class. However, for foreign language teaching, it is only the classroom which serve as venue to use the target language, thus, to make it relevant to the lives of the students and increase the possibility of its usage inside the classroom, it is important to use the contextualized language teaching method. Implementing contextualized language teaching involved two significant factors, namely teachers and instructional materials. Teachers by themselves should be trained to teach the target language using the contextualized method. Native Chinese speaking teachers may be fluent in using the target language, however it lacks the use of local context in teaching, resulting to students using the language in an unfamiliar setting, which will lead to a decrease in their motivation. Therefore, it is more efficient and effective to cultivate local teachers to learn and later teach the language rather than teaching foreign teachers to understand the local context.

Another significant feature to consider in a localized language teaching is the instructional material. In the case of teaching Chinese as foreign language in the public high schools in the Philippines, teachers are using localized instructional materials. Mahabadi (2013) claimed that foreign language learners performed better when localized materials were incorporated in teaching. Localizing instructional materials is the process of including contents, especially vocabulary words that are widely used in the local setting, and removing irrelevant contents. Mediha \& Enisa (2014) found out that contextualized method was more effective than the traditional method in enhancing learners' vocabulary knowledge in a foreign language classroom. The Philippine Department of Education is currently using the localized version of the Happy Chinese (Kuaile Hanyu). The lesson matrices and learning modules were crafted in accordance with the contents of the Filipino version of the Happy Chinese.

The availability of local Chinese language teachers and localized instructional materials such as the Filipino version of Happy Chinese has been instrumental in the successful implementation of Chinese language program in the Philippines. Furthermore, the localization of 
the Chinese teachers has reduced the impact of pandemic in the Chinese language education of the Philippines.

The success of the localization of Chinese teachers in the Philippines was manifested in the results of the recent Evaluation of the Philippine National Foreign Language Program in Public Secondary Schools conducted by the Bureau of Curriculum Development of the Philippine Department of Education, which found out that the learners, teachers, and school heads, are generally satisfied with the implementation of the Special Program in Foreign Language, which includes the Chinese Mandarin Program (Andaya et al., 2020).

\section{Conclusions}

Through the in-depth review of the existing studies and pertinent documents, the researcher concluded the following:

1. The localization of Chinese teachers in the Philippines was done through three modes of training, namely in-service teachers' training, undergraduate degree for Chinese language teaching, and master's degree in Chinese language teaching.

2. The localization of Chinese teachers, which include the localization of instructional materials, has been instrumental in addressing the absence of Chinese volunteer teachers and uniformed instructional materials during the pandemic.

3. The localization of Chinese teachers adopted the use of educational technology to provide opportunities for the continuity of learning for both students and teachers in the midst of pandemic. The teaching and learning resources have been enriched through the use of technology. For teachers' continuous training and professional development, online distance training was utilized. On the other hand, students can access online instruction, radio-based or tv-based instruction. Furthermore, self-directed learning modules have been crafted for those students who don't have access to technology and other resources.

\section{Recommendations}

With the hope that this study would contribute in the field of foreign language teaching and learning, and to provide valuable inputs for the future development of the Chinese language education in the Philippines and the rest of the world, the researcher, in reference with the findings and conclusions of this study, recommended the following possible course of actions:

1. The Confucius Institute Headquarters can consider virtual deployment of teachers by assigning CVTs to Confucius Institutes in foreign countries who will handle online language classes. The said course of action would ensure the continuous implementation of Chinese language programs, including the training of local teachers, in the midst of pandemic. Chinese universities may also offer their faculty to foreign universities to teach Chinese language while the travel restriction or ban is still implemented.

2. Confucius Institutes around the world should consider to cultivate local teachers for Chinese language to lessen their dependency to the importation of Volunteer Chinese Teachers. The Localization of Chinese teachers will serve as the long-term solution for the scarcity of qualified teachers for Chinese language.

3. Confucius Institutes should continue in developing localized teaching and learning materials for Chinese language to promote contextualized language learning.

4. Confucius Institutes and educational institutions around the world can consider developing online portals for localized instructional materials for Chinese language teaching. 
5. To further promote learning of Chinese language, Confucius Institutes may consider developing self-directed or self-paced learning modules.

6. The findings of this paper can be used as reference material to further enhance and improve the implementation of the Chinese as foreign language program of the Philippine Department of Education.

7. The future researchers may explore the historical data of Chinese language learners of a particular locale to validate the effectiveness of distance online learning.

Declaration of conflicting interest

The researcher declares no conflict of interest.

Funding acknowledgement

The researcher did not receive any financial support or subsidy from any organization in the conduct of this study.

\section{References}

Adil, P. T., Policarpio, P. H., \& Pamintuan, C. F. (2020). A communicative analysis of language functions in the Chinese as a foreign language (CFL) textbook: The case of happy Chinese. Universal Journal of Educational Research, 8(8), 3725-3733. https://doi.org/10.13189/ujer.2020.080853

Andaya, J., Buhat, T., Calapit, A., Delos Trinos G., Domingo, R., Fajardo, W., Ferriols, A., Gusano, R., Santos, A., Soliven, S. (2020). Evaluation of the Philippine National Foreign Language Program in Public Secondary Schools. International Journal of Language and Linguistics. 8(6), 240-245. https://doi.org/10.11648/j.ijl1.20200806.11

Aspers, P. \& Corte, U. (2019). What is Qualitative in Qualitative Research. Qualitative Sociology, 42, 139-160. https://doi.org/10.1007/s11133-019-9413-7.

Bee, Y. (2015). The Today and Tomorrow of Chinese Education in the Philippines, Chinese Language Teaching and Education in a Globalizing Southeast Asia, Manila, August 17-18, 2012, Philippines: International Society for the Study of Chinese Overseas and Confucius Institute at Ateneo de Manila University

Cambridge University Press. (2020). Meaning of localization in English. https://dictionary.cambridge.org/us/dictionary/english/localization

Center for Language Education \& Cooperation. (2020a). Teachers: Overview. http://www.chinese.cn/page/\#/pcpage/project?id=167

Center for Language Education \& Cooperation. (2020b). Cooperation on Teacher Training between Chinese and Foreign Universities. http://www.chinese.cn/page/\#/pcpage/project?id=167

Center for Language Education \& Cooperation. (2020c). Training of Local Chinese Language Teachers. http://www.chinese.cn/page/\#/pcpage/project?id=167

Center for Language Education \& Cooperation. (2020d). Volunteer Chinese Language Teachers. http://www.chinese.cn/page/\#/pcpage/project?id=167

Corbin, J.M. \& Strauss, A.L. (2015). Basics of Qualitative Research. California: Sage Publications

Fan, Q. (2005). A tentative study of "the Philippines Mode" by Chinese volunteer teachers. Journal of Yunnan Normal University, 3(6), 22-25.

Gusano, R. (2019). Special Program in Foreign Language (SPFL): Updates and Policy, SPFLChinese Mandarin Principals' \& Supervisors' Forum, July 25, 2019, Angeles University 
Foundation, Angeles City

Hanban. (2020). Volunteer Chinese Teacher Prom. http://english.hanban.org/volunteers/node 9807.htm\#no1

Labiste Jr, J. (2019). Contextualization in English Language Education: Navigating the Place of Maritime Culture in Philippine English Language Teaching. Asian EFL Journal. 23. 83-108.

Mahabadi, S. (2013). The role of localized materials in learning of FFL students. Journal of Languages and Culture, 4(5), 65-74. https://doi.org/10.5897/JLC12.031.

Mediha, N., \& Enisa, M. (2014). A Comparative Study on the Effectiveness of Using Traditional and Contextualized Methods for Enhancing Learners' Vocabulary Knowledge in an EFL Classroom. Procedia - Social and Behavioral Sciences, 116, 3443-3448. https://doi.org/10.1016/j.sbspro.2014.01.780

Palanca, E. (2002). A Comparative Study of Chinese Education in the Philippines and Malaysia. Asian Studies, 38 (2), 30-62.

Philippine Department of Education. (2012, May 14). DepEd enhances training on foreign languages, adds Chinese. https:/www.officialgazette.gov.ph/2012/05/14/deped-enhancestraining-on-foreign-languages-adds-chinese/

Philippine Department of Education. (2019, December 12). DepEd, Confucius Institute Headquarters ink agreement on upskilling teachers. https://www.deped.gov.ph/2019/12/12/deped-confucius-institute-headquarters-inkagreement-on-upskilling-teachers/

See, D. (2015). Exploring the Development Trend of Chinese Education in the Tertiary Level (Philippines), Chinese Language Teaching and Education in a Globalizing Southeast Asia, Manila, August 17-18, 2012, Philippines: International Society for the Study of Chinese Overseas and Confucius Institute at Ateneo de Manila University

Starr, D. (2009). Chinese language education in Europe: the Confucius Institutes. European Journal of Education, 44(1), 66-82.

The World Bank. (2020). How countries are using edtech (including online learning, radio, television, texting) to support access to remote learning during the COVID-19 pandemic. https://www.worldbank.org/en/topic/edutech/brief/how-countries-are-using-edtech-tosupport-remote-learning-during-the-covid-19-pandemic

Tribus, A. C. (2017). The Communicative Functions of Language: An Exploration of Roman Jakobson's Theory in TESOL. MA TESOL Collection. 723. https://digitalcollections.sit.edu/ipp_collection/723

UNESCO. (2020, February 6). Learning through radio and television in the time of COVID-19. https://en.unesco.org/news/learning-through-radio-and-television-time-covid-19

United Nations. (2020). Policy Brief: Education during COVID-19 and beyond (August 2020) World | ReliefWeb. August, 26. https://reliefweb.int/report/world/policy-brief-educationduring-covid-19-and-beyond-august-2020

World Health Organization. (2020, March 11). WHO Director-General's opening remarks at the media briefing on COVID-19 - 11 March 2020. https://www.who.int/dg/speeches/detail/whodirector-general-s-opening-remarks-at-the-media-briefing-on-covid-19---11-march-2020.

Yang, S. (2014). Several Thoughts on Current Chinese Education in the Philippines. International Conference on Education Technology and Social Science. Atlantis Press. 196-200.

Zhang, H. (2012). The Nature of Volunteer Chinese Teaching launched by the Hanban. University of Pittsburgh.

Zhang, S. (2015). Developing Local Teachers for Chinese Language in the Philippines, Chinese 
Language Teaching and Education in a Globalizing Southeast Asia, Manila, August 17-18, 2012, Philippines: International Society for the Study of Chinese Overseas and Confucius Institute at Ateneo de Manila University 